\title{
Indeterminate Continuous Cardiotocography Pattern
}

National Cancer Institute

\section{Source}

National Cancer Institute. Indeterminate Continuous Cardiotocography Pattern. NCI

Thesaurus. Code C111772.

Indeterminate fetal heart rate pattern. Not predictive of abnormal acid-base status at time of observation but insufficient to classify pattern as Category I or III. Example patterns include: minimal or marked variability, absent variability without recurrent decelerations, absence of induced accelerations after fetal stimulation, recurrent variable decelerations with minimal or moderate variability, prolonged decelerations, recurrent late decelerations with moderate variability and variable decelerations with slow return to baseline, overshoots or shoulders. 